\title{
Del currículum nulo al "currículum proscrito" o de las formas de segregación de contenidos en la práctica escolar ${ }^{1}$
}

\author{
Edisson Cuervo Montoya ${ }^{2}$ \\ Universidad de Antioquia
}

Resumen: En los estudios del currículum se encuentran sendos análisis e investigaciones tanto del currículum explícito (oficial) como del currículum implícito u oculto, presentándose allí las implicaciones que ambos niveles de lo curricular derivan en los procesos de enseñanza-aprendizaje que se llevan a cabo en los ámbitos escolares del mundo. Otro es el caso del currículum nulo, que tiene que ver con la parte anulada del conocimiento escolar y que ha sido poco tratado teóricamente en lengua castellana. Este currículum nulo (null curriculum) adquiere mayor acento en aquello que nombramos como currículum "proscrito", el cual desaparecer o segrega los conocimientos sobre temáticas complejas que deben ser tratadas en los ámbitos escolares, proscribiéndose o expatriándose el saber sobre la violencia armada, distintas formas de la sexualidad u otros contenidos que se prefiere no tratar en el centro educativo. El presente artículo pretende desarrollar teóricamente ambos conceptos, destacándolos como constitutivos de los entornos escolarizados y por ende de los procesos de aprendizaje que se desatan en los mismos.

Palabras clave: currículum oculto, currículum nulo, currículum proscrito.

Abstract: In the curriculum studies of there are many curriculum research and analysis of the explicit curriculum (official) and the implicit or hidden curriculum, performing there the implications of both levels of the curriculum arise in the teaching-learning, which are held in found school settings in the world. Another is the null curriculum, which has to do with the annulled part of school knowledge and has been recently treated theoretically in Spanish. This null curriculum (null curriculum) delves into what curriculum named as "curriculum outlaw" which appear or disappear does best knowledge of complex issues that must be addressed in school settings, or prohibited; banishing knowing about gun violence, different forms of sexuality or other content prefer not to try at school or college. This article aims to develop both theoretical concepts, highlighting them as constitutive of educational environments and therefore the learning process is achieved in them.

Keywords: hidden curiculum, null curriculum, outlaw curriculum.

\section{Introducción}

Las investigaciones sobre el currículum centran su interés, por su propia naturaleza, en los aspectos que tienen que ver con el conocimiento que es seleccionado y ordenado para un proceso de enseñanza y aprendizaje. De ellas, es claro que el currículum oficial y explicito ha recogido una particular atención investigativa, no

\footnotetext{
${ }^{1}$ El presente escrito hace parte de la investigación doctoral intitulada "Violencia directa en los curricula de instituciones educativas emplazadas en contextos de conflicto armado" que fue presentada en la Universitat de Valencia y dirigida por el profesor Dr. José Gimeno Sacristán y el profesor Dr. Ángel San Martín Alonso.

${ }^{2}$ Doctor en Ciencias de la Educación por la Universidad de Valencia (España), Máster en Investigación Educativa por la Universidad de Alicante (España), Licenciado en Filosofía por la Universidad de Antioquia (Colombia). Coordinador de Asuntos Curriculares (Universidad de Antioquia - Vicerrectoría de Docencia) - Profesor Instituto de filosofía y Facultad de Educación Universidad de Antioquia. Email: edisson.cuervo@udea.edu.co
} 
siendo ella por su puesto exclusiva, por razón del impacto en las investigaciones sobre el currículum que devinieron del interés académico por la denotación implícita u oculta del currículum mismo: el currículum oculto (Da Silva, 2001), así mismo la noción de currículum nulo, ha posibilitado una serie de reflexiones e indagaciones por los contenidos que definitivamente no están en los procesos de enseñanza de los distintos niveles de formación, derivándose preguntas tan relevantes como aquellas que se cuestionan por ¿quién o quiénes anularon o anulan conocimientos del currículum?, ¿qué relevancia tiene preguntarse por los conocimientos o contenidos que no están (ni estarán) en las aulas?, ¿qué tipos de conocimientos se anulan?

Preguntas todas que derivan en un terreno que no ha sido explorado de manera tan amplia como se requiere: el currículum nulo en educación básica y media. Ello para tener una comprensión global tanto de los contenidos que se incluyen, pero también de los conocimientos que se desechan, ahondándose el interés por este tipo de contenidos, cuando se pasa a anularlos por desconocimiento de los mismos, a silenciarlos de manera expresa y voluntaria, en cualquiera de los niveles de objetivación curricular.

Es importante entonces auscultar en dicho terreno de conocimientos que han sido separados o negados de las aulas de clase y que, de una u otra forma, vienen a ser parte del universo de asuntos que requieren ser abordados en el campo curricular, como terreno sustantivo del conocimiento ordenado y dispuesto para que sea recibido o no, por las nuevas generaciones, pasemos pues a esta trayectoria conceptual de lo anulado a lo proscrito en materia curricular.

\section{Idea inicial: el currículum nulo}

La idea central del currículum nulo o negado debe entenderse como lo que "no está" o el conocimiento que es inexistente en el currículum escolar, esto es, lo que no se habla o no se incluye en él. Son los contenidos que se encuentran anulados en la selección de conocimientos que se hace en el currículum, para un proceso de enseñanza. Dicho concepto es integrado a las discusiones académicas sobre el currículum por Eisner (1979), quien entiende que más allá de un currículum explícito y otro implícito, existe en el ámbito escolar un currículum inexistente o nulo. Y su justificación de abordar lo paradójico de preguntarse por la existencia de lo que se señala de entrada es inexistente, no es de menor interés para nosotros en educación:

\footnotetext{
"Mi tesis es que, lo que las escuelas no enseñan puede ser tan importante como lo que enseñan. Sostengo esta posición porque la ignorancia no es simplemente un vacío neutral, sino que tiene efectos importantes en el tipo de opciones que uno es capaz de considerar, en las alternativas que uno puede examinar y en las perspectivas desde las cuales se puede ver una situación o problema." (Eisner, 1979, p. 97)
}

Es importante preguntarse por los contenidos que están anulados o son inexistentes en el currículum escolar, entre otras cosas, porque sabemos que el maestro, desde miradas más contemporáneas y críticas de la educación, entre sus responsabilidades estriba no ser sólo un reproductor de conocimientos e ideologías, sino un investigador y productor de saber (Torres, 2007; Da Silva, 2001), que comprende los flujos de significado y aprendizaje, que están a merced de los educandos, e incluso sabe del conocimiento que no se encuentra incluido en él. 
$\mathrm{Y}$ es que aquello que se aprende en el acto educativo gravita por supuesto en lo que es manifiestamente evidente y lo que no, pero también se aprende de lo que está ausente, y compartimos la ejemplificación de ello con Acaso (2013), cuando nos habla de la nula o exigua presencia de la mujer en la asignatura de historia y su respectivo aprendizaje, de que el papel de la mujer no ha sido tan relevante en la historia del arte, por ejemplo. Así mismo Torres (1993) nos hace caer cuenta de ello, cuando nos habla de unas culturas negadas y silenciadas en las escuela y el currículum de esta, entre otras, "las culturas infantiles, juveniles y de la tercera edad, las étnias minoritarias o sin poder, el mundo femenino, las sexualidades lesbiana y homosexual, el mundo rural y marinero, las voces del Tercer Mundo" (p. 61), entre otros inexistentes o de precaria presentación de temas en los currícula, como por ejemplo la cultura del sicariato (Carrión, 2009), la cultura de la guerra (Nahoum, 2002), el necrocapitalismo (Banerjee, 2008), entre otros.

Ahora bien, con una escasa presencia en la investigación educativa de producción hispanohablante, el concepto de currículum nulo o negado, dice el profesor Antonio Bolívar Botia en Bolívar, Mata y Rodríguez (2006), se refiere a aquellos aspectos excluidos y ausentes del propio currículum, retomando para tal explicación el trabajo de Arrieta de Meza y Meza (2001) en donde se expone toda una gama de variantes o niveles del mencionado concepto de currículum nulo asociado a diversas causas, entre otras, el currículum nulo por omisión, por frondosidad, por preferencia del docente, por falta de incentivo, por falta de preparación del propio docente, por desfase del conocimiento, por superficialidad o por tradición, entre otras causas.

De igual manera y curiosamente sin referencia alguna a la producción inglesa sobre el término, pero no por ello menos interesante, Guevara (2000) intenta una definición propia en la cual refiere que "al Currículum Nulo lo constituyen experiencias que, aunque pudieran vivirse en la escuela, intencionalmente no se provocan". (p. 1) Y decimos que resulta ser interesante también ese intento de definición, ya que apunta de manera explícita a un carácter voluntario e intencionado de no provocar determinadas experiencias educativas en el ámbito escolar.

Pero, como lo importante no es quedarnos simplemente con decir que el currículum nulo es una realidad escolar que más o menos se define como "lo que no está contemplado" o que son las "experiencias educativas no provocadas de manera intencionada", interesante será pensar por qué no está lo que se niega en el mismo, reflexionando en quién lo quita o no lo agrega y sus particulares motivaciones para ello. ¿Será el maestro, el Ministerio de Educación, las editoriales? ¿quién, cuáles son las razones para esa práctica? Preguntas de gran relevancia en nuestro caso, toda vez que se ha dicho que el currículum es una selección de conocimientos, un conjunto de saberes que direcciona el saber mismo de los educandos. ¿Qué razones pueden existir para ser llevada a cabo dicha exclusión? Siendo claro y manifiesto el argumento de una de las razones para tal anulación, sea el imposible abordaje e inclusión de todo el conocimiento producido por el ser humano en un mero programa de estudios (Gimeno, 1988, 2010), además de las razones didácticas que lo aconsejan en cada caso particular de los saberes específicos y que por supuesto tiene total coherencia y sentido desde un punto de vista epistemológico. En este sentido Beltrán (1994) nos habla de "determinaciones curriculares [...] de carácter epistemológico, es decir, ligadas a ciertas reglas propias de la construcción del conocimiento mismo" (p. 377). Sería bastante difícil tratar de explicar las últimas elaboraciones teóricas de física de partículas sobre el Bosón de Higgs a personas que no tuvieran bases e incluso cierta experticia en teoría matemática y física. 
Pero en realidad lo que nos interesa acá es profundizar en las razones de dicha negación o anulación curricular, para tratar de develar otras causas no tan explícitas, ya que como dice en torno a ello el mismo Gimeno (2010), "la cultura que ocupa los contenidos del currículum es una construcción cultural especial, "curricularizada", porque se selecciona, se ordena, se empaqueta, se imparte y se comprueba de acuerdo con moldes sui generis" (p.26) Resultando con ello que es decidido que los educandos conozcan unas cosas y otras no, así también como que sus comportamientos sean de ésta o aquella forma. ¿Qué será entonces lo que no se incluye en el currículum?, ¿por qué no se le incluye?, ¿podríamos llegar a saber si existen temas o saberes que no se incluyen en determinados curricula?

Para abordar tales cuestionamientos, consideramos clarificador, a esta altura del escrito, echar mano del esquema de distribución de competencias curriculares propuesto por Gimeno (1988) y que nos permite ver de forma clara, en términos metodológicos, a diferentes instancias de decisión curricular (Beltrán, 1994) en las cuales pudieran centrarse las responsabilidades de ese acto de anulación de contenidos por parte de varios o de alguno de los agentes de decisión curricular (Beltrán, 1994) que intervienen, en tanto que son quienes actúan en cada uno de esos llamados niveles de competencia curricular, no siendo otros que:

\author{
1. El Estado \\ 2. La Comunidad autónoma (para el caso español) \\ 3. Los Centros (educativos) y \\ 4. Los profesores.
}

En cuanto al Estado y las comunidades autónomas (para el caso español) es irrebatible y manifiesto que en el trasfondo existan razones de motivación política para realizar tales omisiones; es más, adherimos a Beltrán (2010) cuando dice que "la peculiar conformación del currículum, relativa a los procesos institucionalizados de enseñanza y aprendizaje, hace de él un ámbito privilegiado para que puedan cumplirse a través suyo acciones de poder cuya realización o éxito político sea susceptible de quedar sometido a algunos de los múltiples procedimientos de control" (p. 49). Esto es que, para nuestro caso puntual en torno al currículum nulo o negado, los ejercicios que ejecutan tal omisión sean la ejecución de acciones de poder que muy bien pueden materializarse y ser visibles en las agendas de reforma de los distintos grupos políticos en la administración del Estado o de las comunidades autónomas, caso concreto en el Estado español las distintas reformas educativas en menos de 23 años (desde la LOGSE hasta la LOMCE), siendo más que clarificadores los debates curriculares y políticos que se han dado en cada legislatura para la supresión o no de algunas asignaturas o la supresión de otras. De igual manera, y con respecto a los centros educativos y el profesorado, podríamos decir que las motivaciones son, entre otras, de naturaleza política igualmente. Lo cual explicaría el hecho de que en estos niveles de agenciamiento y gestión del currículum, sus agentes omitan, excluyan, descarten y prescindan de algunos contenidos curriculares.

Ahora bien, habíamos dicho que en lengua castellana el despliegue investigativo de tal concepto es bastante precario e insuficiente, no así en lengua inglesa, donde por lo menos encontramos algunas investigaciones que incluyen cierta indagación en el mismo, de forma teórica y/o empírica. Como es el caso de Flinders, Noddings y Thornton (1986), quienes si bien dicen que la noción de currículum nulo no se puede definir en términos precisos por ser una categoría más bien ambigua, 
relacionándola con aquellos contenidos de los que se prescinde en el currículum y que puede ser identificados sólo en relación con lo que se valora educativamente como significativo, llegan dichos autores a la conclusión de que sí vale la pena la utilización del concepto de currículum nulo en ciertas prácticas de las áreas de desarrollo curricular, la deliberación y la evaluación del currículum. Los autores reconocen dos dimensiones del currículum nulo, una que tiene que ver con los procesos intelectuales y otra que tiene que ver con el contenido mismo que no se abriga en el currículum.

Similar postura encontramos en Torok (2007), cuando en un ejercicio de rehistorización y reflexión sobre la necesidad de una mayor recontextualización del currículum, nos recuerda la relevancia de dicho concepto de currículum nulo desde los principios de inclusión y exclusión que rigen al currículo mismo en sus diseños, criticando el hecho de que se decantan dinámicas de favorabilidad de una clase social frente a otra, desde la anulación de contenidos.

$\mathrm{Y}$ es que, a la hora de reflexionar sobre un tema de tal envergadura como la violencia directa en el currículum escolar, es relevante cuestionarse sobre qué anular de dichos contenidos o porqué están anulados los que ya lo están. A este respecto Totten (2001) piensa en clave de currículum nulo el no estudio de los genocidios distintos al holocausto nazi, dejando claro que si bien es muy relevante el estudio de dicho holocausto, lo es igualmente la presencia en el currículum y estudio de estos, ya que el no abordaje educativo de otros genocidios o una mención de paso de los mismos, puede dejar el mensaje implícito en los educandos de que los otros genocidios no son tan importantes o que el propio holocausto fue una aberración del lejano pasado, no asegurándose así que ello no pueda volver a ocurrir.

De igual manera, Scarlett (2009) reflexiona sobre el problema de que se encuentren anulados de los currícula de ciencias sociales de educación secundaria, los temarios de justicia transicional, comisiones y tribunales de verdad, sistemas de reparación y la conmemoración del pasado, como estudio de las formas en que las sociedades que salen de un conflicto violento y de regímenes represivos, logran la paz y la reconciliación a través del reconocimiento de los derechos humanos como proceso de humanización.

Assemi y Sheikhzade (2013), valorando la importancia de que tanto los sistemas educativos como el profesorado reflexionen sobre el conocimiento que se anula o niega en el currículum, diferencian tres elementos a tener en cuenta cuando se piensa en el currículum nulo. Uno de ellos es cuando se trata de actos deliberados e intencionados de eliminación y exclusión de contenidos por parte de los responsables del sistema político y de la educación, los editores de libros de texto y los administradores educativos, nombrando ello como currículum nulo previsto. Por otra parte, el currículo nulo implementado por funcionarios de la escuela o los mismos profesores y finalmente el currículum nulo experiencial, que se nos alude lo que los mismos estudiantes no consideran en sus áreas de interese y talento personal, por lo tanto, queda excluido.

Ahora bien, tales consideraciones sobre el currículum nulo podríamos muy bien cobijarlas en torno al concepto de ideología en términos curriculares y el carácter hegemónico de algunos discursos en la base del diseño curricular, esbozadas por los autores de tradición netamente crítica, y que viabilizan algunas posibles explicaciones de la negación, anulación o invisibilización de ciertos contenidos curriculares, que pudiera ser la raíz central de varias de las diez y seis (16) categorías que el texto de Arrieta De Meza y Meza (2001) diferenciaba en torno al currículum nulo, como por ejemplo aquella que vincula al currículum negado una causa de voluntaria omisión y que "se produce cuando no se incluyen en la programación importantes puntos necesarios para su aplicación durante el ejercicio profesional" (p. 4). Es importante 
aclarar que aunque el currículum nulo por omisión sea una idea propuesta por Arrieta de Meza y Meza (2001), ambos autores reconocen que en realidad se trata de una interpretación de lo propuesto por Posner (1998) "cuando hace mención a los temas de estudio no enseñados" (p. 4). Dicha idea de currículum oculto por omisión nos decanta en que existe alguien o un organismo institucional que omite incluir contenidos en el currículum, un acto de omisión que denota la intencionalidad manifiesta de "descartar".

Por la anterior vía podemos apuntar a Guevara (2000), cuando refiere que dicha omisión resulta ser consciente y vinculada a opciones ideológicas, que si bien no son exclusivas, están de igual manera presentes. Y en este sentido son más que ilustradores los trabajos teóricos de Apple $(1986,1997)$ y el hacer académico de los teóricos críticos del currículum (Giroux, 2001, 2003 y Mclaren, 1994, 1997) quienes nos brindan unas sugerentes líneas de respuesta, desde sus particulares análisis críticos, reflexionando en los elementos ideológicos y políticos que mueven la inclusión o no de determinados contenidos en el currículum. Además, por el hecho de emplear en sus reflexiones categorías como ideología, hegemonía, poder, clase social, capitalismo, relaciones sociales de producción, concienciación, emancipación y liberación, pudiendo responder igualmente al problema que suscita el currículum nulo, en torno a las connotaciones ideológicas circunscritas a ese currículum escolar, que no permite que se incluyan ciertos contenidos en él mismo, toda vez que no responden a los intereses de la estructura hegemónica dominante porque "el control del sistema cultural de una sociedad, el conocimiento que conservan y producen las instituciones, y de los actores que trabajan en ellas es esencial en la lucha por la hegemonía ideológica" (Apple, 1997, p. 31).

Así mismo, Torres (1991) en sus análisis del concepto de ideología nos dirá que ésta tiene principalmente por función en la sociedad "la constitución y modelado de formas bajo las cuales las personas viven y construyen significativamente su realidad, sus sueños, deseos y aspiraciones" (p. 17), siendo la escuela (y por ende el currículum) uno de los mecanismos de reproducción de aquella (Althusser, 1970). Y es que toda vez que dicha "ideología traduce [...] una visión del mundo, una perspectiva sobre las cosas, acontecimientos y comportamientos" (Torres, 1991: 18), el currículum nulo es resultado de criterios de no transmisión de ciertos conocimientos de manera intencionada para la reproducción de determinados ciudadanos. Y ejemplos de control ideológico y hegemónico de los currícula son muchos, desde los mismos orígenes de educación para la ciudanía en la Francia Republicana (Dubet, 2003), los direccionamientos y control del currículum en dictaduras de regímenes políticos cerrados, bien sean antiguos o presentes y los direccionamientos ideológicos que el propio capitalismo hace en el grueso de sistemas educativos mundiales (Giroux, 2001, 2003; Mclaren, 1997; Torres, 2007).

De otra parte y dirigiendo la mirada hacia los dos restantes niveles de competencia, tenemos que mencionar que ellos (profesores y centros), en potencia, pueden también omitir y excluir contenidos del plan de estudios del centro escolar, y este acto no es para nada distinto a la planificación misma de la clase; el ejercicio de la práctica supone un acto selectivo de incluir y descartar unos contenidos sobre otros. Pero, ¿qué ocurre para que esos responsables de los centros educativos, así como maestros y maestras excluyan contenidos curriculares que versen sobre problemáticas que afectan de manera explícita y manifiesta la comunidad educativa o la sociedad a la que está circunscrita la institución educativa? Temas como la legitimidad de las formas distintas de la sexualidad o como (hasta hace muy poco) el tratamiento conceptual de la violencia de género en los hogares y la violencia armada y política han sido temas de los cuales o no se habla o se niega a hablar, para el caso de algunos contextos sociales, o se habla demasiado poco en los currícula escolares. Pero son 
aspectos de la vida de los ciudadanos que están ahí y que no se pueden obviar. ¿Cómo obviar en el currículum escolar que existen personas con elecciones sexuales diferentes a lo que podríamos llamar socialmente como conductas "normales"? ¿Cómo se llegaron a excluir del currículum los actos brutales y continuados a los que se sometió la mujer históricamente? y (para el caso específico de algunos países) ¿cómo no hablar del contexto de violencia armada y política que los educandos mismos viven en sus casas, barrios, ciudades y sociedad en general?

Scarlett (2009) menciona que uno de los problemas o causas que existen para la no inclusión de temarios (en su caso particular, los de justicia transicional) en los currícula escolares en los EEUU, sea la llamada rendición de cuentas, a través de las pruebas y test locales o federales tan en boga de los sistemas educativos contemporáneos. Sale a escena así que una de las justificaciones para la no inclusión o negación de contenidos precisamente sea, en tenor del centro educativo en su conjunto, su interés de ceñir sus planes de estudio a los requerimientos en materia evaluativa de la educación, problemática ampliamente discutida por distintos autores y en la cual no vamos a profundizar en el presente escrito, salvo referenciar los trabajos en esta línea de problematización de la evaluación y el currículum de Gimeno (2013), Bolívar (2008), Whitty y Power (2008) y Franklin y Johnson (2006).

Por otro lado, Arrieta de Meza y Meza (2001), en su ejercicio de categorización del currículum, nos hablan aparte del currículum nulo por omisión, del currículum nulo por falta de preparación del docente y por desfase de conocimiento. Algo a lo que Guevara (2000) identifica por causa de simple y llana ignorancia en los maestros, originada en el colectivo docente (argentino en su caso) por un magisterio constituido por hijos/as de obreros, de trabajadores no calificados y de clases medias bajas, fundamentalmente. Con poco acceso a los "bienes culturales" que la escuela espera transmitir, propios de los sectores que ejercen supremacía en la sociedad. Así es que hay ciertos temas que no se enseñan en la escuela porque no se saben, más allá de que se hallen expresamente indicados en los Diseños Curriculares, o en los Contenidos Básicos Comunes a los que hicimos alusión. (Guevara, 2000)

A lo que las ideas de Scarlett (2009) también se suman desde el caso norteamericano, cuando reconoce que "los educadores probablemente carecen de los conocimientos básicos para incorporarlos a su plan de estudios sin investigación adicional." (p. 171). Esto es, que el reconocimiento de que el currículum nulo tiene por otra de sus causas el desconocimiento en cabeza del profesorado, bien sea de la relevancia del contenido anulado o negado como tal o de las metodologías para poder integrarlo al currículum del centro educativo por vía del proyecto educativo de centro o de las respectivas unidades didácticas. Esto es, el currículum nulo por fallas metodológicas que se da "por el escaso conocimiento que tenga de la metodología el profesor encargado de una signatura" (Arrieta de Meza y Meza, 2001, p. 5).

Por otra parte, también Ahwee et al. (2001) en un formato experimental con estudiantes de doctorado, exploran el concepto de currículum nulo, examinando en primera medida algunas contribuciones teóricas y proporcionando estudios de caso anecdóticos, a manera de ejemplos, de los cuales se extrae la forma en que opera el currículum nulo, que obnubila partes relevantes de la historia de un pueblo, su literatura y la cultura del mismo. Además de la anulación de temáticas como el género, los grupos marginados y las identidades étnicas (para el caso norteamericano, los negros). Teniendo de presente que,a través de dichas exclusiones y anulaciones de contenido, se dejan totalmente claras las expresiones culturales y políticas de importancia para la sociedad que circunscribe la escuela. Quedando sostenidas y estabilizadas, a través de dicha anulación y negación, las costumbres y los valores tradicionales de determinada sociedad, reconociéndose así "la naturaleza 
profundamente política del currículum oculto y nulo. [...] debido a que operan a nivel cultural en gran parte inconscientemente" (Ahwee et al., 2001, p. 41).

No podemos desconocer, así mismo, las categorías conceptuales que se manejan bajo las llamadas teorías post-críticas del currículum, que también nos ayudarían a reflexionar sobre el problema de negación de contenidos en el mismo y que según la diferenciación propuesta por Da Silva (2001) ellas tienen que ver con los debates en torno a "la identidad, alteridad, diferencia, subjetividad, significación, discurso, relaciones de saber-poder, representación, cultura, género, raza, etnia, sexualidad y multiculturalismo" (p. ). Conceptos que nos ayudarían a problematizar aún más aquella mencionada no inclusión especifica de algunos contenidos curriculares. Ideas discutidas todas en los procesos teóricos de la postmodernidad, el posmodernismo, el posestructuralismo y los estudios culturales. Pero, con el fin de no vernos desbordados por tal amplitud de conceptos y tradiciones conceptuales aún en desarrollo, aludamos brevemente y para nuestro caso específico, a la noción de cultura y su consecuente idea de política cultural (Giroux, 2001), para relacionarlas con la idea de currículum nulo en la escuela.

Decíamos en el erior apartado que por cultura adheríamos las ideas de Geertz (1957), quien entendía por ella una "trama de significados" con la cual los seres humanos interpretan su existencia y experiencias, además de conducir sus acciones. La escuela es una transmisora de cultura (Pérez Gómez, 2004) que conjuntamente conformada por múltiples culturas (Pérez Gómez, 2004), visibiliza, legitima y reproduce elementos culturales hegemónicos, además de invizibilizar y anular otros muchos (Torres, 1993, 2010). Siendo claro que la escuela, según (Fernández, 1999) gestiona colectivos más que individuos, allí los alumnos aprenden a comportarse como sus miembros activos, porque así es como la sociedad espera que se comporten el día de mañana (p. 35).

Sabemos de igual manera que los estudios culturales se han preguntado desde sus orígenes por la manera en que el entorno social (y el educativo por supuesto) afectan las formas de relación entre las personas, en clave de edad, género o identidad étnica (Urteaga, 2009), derivándose un flujo importante de investigadores e investigaciones sobre el particular hecho de que existe en los grupos sociales un conjunto de representaciones o trama de significados que se sobreponen a otros, anulándolos, para normalizar formas de comportamiento legitimas para un específico entorno social. Ejemplos de ello pueden ser múltiples, y más en materia curricular, baste con nombrar dos de estos, el primero tiene que ver con que a través del currículum norteamericano de principios del siglo XX se buscará mediante "la apreciación de música [...] la anulación de características degeneradas asociadas con poblaciones raciales e inmigrantes" (Popkewitz, 2010, p. 366) específicas. Así mismo sirve de ejemplo, para el caso colombiano, cómo en los procesos de configuración de la ciudadanía "la escuela operó desde finales del Siglo XIX, como instrumento pedagógico privilegiado para catalizar la cultura política dominante [facilitando desde ella misma una idea de] Civilización que se homologa al ideario europeo [...] como bien lo indican los libros de texto de la época" (Árias, 2010, p. 81).

De igual manera llama nuestra atención la crítica presentada por Martínez (2010) a la forma en que los curricula fragmentan la experiencia cultural de los educandos en "múltiples disciplinas académicas", que separan (y a su vez también anulan y niegan) la experiencia ciudadana, desconociendo que "la experiencia social y educativa del sujeto en la ciudad es mucho más amplia de lo que la tradición académica conoce y considera importante" (p. 543), configurándose así lo que a los ojos del mencionado autor, se entiende como el desperdicio de la experiencia y un "desprecio del carácter situado/situacional de los problemas sociales, culturales y 
educacionales" (p. 543) y para nuestro caso el problema de la violencia directa como fenómeno socio-cultural, presente en la escuela, la sociedad y la cultura.

\section{El currículum "proscrito" y sus prácticas segregadoras de determinados conocimientos}

Lo proscrito se relaciona etimológicamente con el término latino proscritus, participio de proscriběre que alude a la publicación de algo en un cartel público. En muchos casos los carteles o anuncios públicos en la antigua Roma, informaban del exilio y destierro al que eran obligados algunos de sus ciudadanos, sentido por el cual, se terminó por relacionar lo proscrito con los expatriados, los expulsados, los desterrados. De igual manera, tal como se referencia en la Real Academia de la Lengua, el término proscribir se usa para denominar el acto de "excluir o prohibir una costumbre o el uso de algo" (DRAE). Como también se llegó a entender por este término, la declaración de "alguien público $[y]$ malhechor, dando facultad a cualquiera para que le quitara la vida, y a veces se ofrecía premio a quien lo entregara vivo o muerto." (DRAE)

Lo proscrito pues, se relaciona con lo no deseado socialmente y a la vez con aquello que merece ser vapuleado de manera pública. Se propone entonces dirigir la mirada y preguntar, hacia los conocimientos que han sido proscritos en algún momento del quehacer escolar. Pero, teniendo claro que abordar en este escrito la totalidad de conocimientos que se excluyen de todas las asignaturas escolares, sería una labor que requeriría una mayor extensión, se propone apelar, a manera de ejemplo, a la enseñanza de la literatura en la educación básica y media, para poder comprender de mejor manera el mencionado fenómeno de proscripción curricular.

Igualmente se debe aclarar que este indagar o discurrir teórico se ha querido realizar de la mano de una palabra que por su misma potencia conceptual permite auscultar los caminos de organización y selección de los conocimientos, que se disponen para los procesos de enseñanza y aprendizaje: el "curriculum". Concepto en el que, si bien no se ahonda en este texto en detalle, se propone entenderlo en un sentido o significado puntual. No siendo otra definición, que aquella que le entiende como esa selección cultural de conocimientos o contenidos que una comunidad ha valorado como importante (Stenhouse, 1991), para ser transmitidos a las nuevas generaciones. Con la no menos relevante característica que propone el profesor Da Silva (2001) cuando afirma que aquellos conocimientos que son seleccionados curricularmente, terminarán por convertir a las personas en lo que son, en su identidad, en los rasgos propios de su subjetividad.

Las formas en que se ama, siente, comprende y se actúa en el mundo, se encuentran mediadas por esos conocimientos que alguien, en algún momento de los procesos formativos, seleccionó. De allí la importancia de que hoy se piense en cuáles son esos conocimientos que han sido desterrados del currículo tanto de literatura, como de las distintas áreas de conocimiento. A manera de ejemplo, el currículum "proscrito" de la enseñanza de la literatura en educación básica y media.

Ahora bien, podemos referir varias preguntas que pueden ayudarnos a ejemplificar dichos ejercicios curriculares de proscripción en la enseñanza de la literatura en educación básica y media: ¿acaso hay componentes relevantes de la literatura que no son abordados en la enseñanza de ella misma? ¿Será necesario y justo desterrar algún género literario de nuestras prácticas educativas? ¿Alguien se atrevería en los tiempos que corren a ponderar como malignos o malhechores, algunas partes literarias, y se sienta por ello con facultad para expatriarlo o escindirlo? Se reconoce lo problemático de fragmentar los textos en educación básica, en tanto ello es un traspié 
en la enseñanza de la misma, por el efecto de imposibilitar con esa práctica que los estudiantes tengan un acercamiento completo a la obra literaria con todo lo que ello implica; y no implica menos que la posibilidad de acceder a distintos conocimientos reales o ficticios, gozar de diferentes experiencias estéticas y por supuesto conocer distintas perspectivas concebir el mundo y actuar en él. Joan Carles Mèlich nos dirá a este respecto que la pedagogía literaria ayuda a "la formación de una razón imaginativa, que sea capaz de narrar sentidos, de inventar sentidos, en plural, porque nunca hay en la vida humana un único sentido, sino sentidos distintos e incluso contradictorios" (Mèlich, 2003, p. 37).

La particularidad pues de la proscripción curricular estriba en el ejercicio voluntario del maestro o de algún otro agente de decisión curricular, de expatriar, desterrar o sentenciar al silencio la literatura misma o una parte de ella; el ejercicio voluntario de negar y anular trozos de la literatura vista en su conjunto. Llamamos, pues, la atención sobre esas posibles prácticas que hacen parte de las dinámicas curriculares en nuestros espacios formativos. Pero, ¿qué se niega? ¿Qué se anula en las aulas? ¿Qué conocimientos sobre literatura se destierran y proscriben en educación básica y media? Válidas preguntas, que por el solo hecho de ser pensadas merece la pena que maestros y maestras, indaguen si existen conocimientos que excluimos voluntariamente de nuestros curricula.

Reflexionando, por ejemplo, en la ausencia de la literatura erótica del currículum de dichos niveles de enseñanza. Una ausencia sostenida en el transcurrir de la trayectoria escolar y reemplazada en muchos casos por la literatura romántica, cuando no simplemente en un ejercicio de anulación y proscripción curricular, que pervierte la relación estrecha entre el ser humano y el erotismo. Manifiesta prohibición de avivar en las mentes de los y las jóvenes de edad escolar, el despertar de su sexualidad y la relación con sus congéneres. Con los exiguos resultados de una básica formación sexual, fundamentada en contenidos sobre anticonceptivos y dirección técnica del uso de los aparatos sexuales. Desde la mencionada negación, anulación y proscripción manifiesta de contenidos escolares que hablen sobre el sentir humano y vital con otro ser, aspecto que la literatura erótica puede ayudar a comprender. Textos como el Heptamerón de Margarita de Angulema escrito en 1558, pueden demostrar que la literatura erótica no es algo tan nuevo ni tan soez. Sin hacer referencia por su puesto, a la literatura pornográfica, que si bien puede ser gusto de algunos y algunas, inimaginable sería para las mentes curriculares, que legislan el saber escolar desde una perspectiva moralista.

Y se opta en este punto del escrito, por no hacer referencia a la literatura lesbiana y homosexual que, a la luz de muchos maestros y maestras de educación primaria, será de inmediato rechazo en cuanto a su lectura en tempranas edades. Desconocedores y desconocedoras de cuentos como "Rey y rey" de las autoras De Haan y Nijland (2005), que narran formas de relación más allá de códices morales. Entre otros textos infantiles, que lejos estarían de la pornografía o la hipersexualización temprana. Documentos literarios que hablan de reconocimiento, diversidad, respeto, amistad y amor, cosas que son al parecer tan claras y sencillas para los niños y las niñas, pero tan complejas y difíciles de entender para muchas personas adultas.

De igual manera pudiese pensarse con respecto a la literatura política, que más allá de avivar peligrosos fervores politiqueros en las jóvenes o infantiles mentes, posibilitarían reconocer las múltiples miradas sobre las relaciones humanas y las formas de concebir al otro, como un sujeto válido de argumentación y de existencia en el mundo. Se ha dicho en este texto que la literatura, ayuda a reconocer diferentes sentidos. Entonces expatriar y proscribir del currículum a la literatura política, 
posibilita en cierto modo, el desconocimiento de que los argumentos y posturas políticas del oponente, puede tener razones y argumentaciones igualmente válidas. Curándose así, posiblemente, a las jóvenes generaciones, de las luctuosas prácticas de anular a quien concibe el mundo con diferentes matices. O excluirlo de la democrática tarea de confluir como iguales en sociedades como la colombiana que históricamente ha estado inmersa en problemas políticos y de violencia social. Alejar la literatura política de los "curricula" en educación básica y media, puede dejar la formación política a los avatares de la deformación, que los medios masivos de comunicación realizan con sus espectadores.

Es claro que la práctica curricular supone ejercicios de selección y organización de conocimientos, decidirse por el análisis de un cuento o un poema en una clase, supone dejar por fuera todos los otros cuentos y poemas existentes, por lo menos en ese espacio temporal de la clase. Sin embargo, es importante apuntar a la reflexión sobre el currículum proscrito y su materialización en prácticas de anulación voluntaria de determinados contenidos y conocimientos, en educación básica y media.

\section{A manera de conclusión}

Con lo dicho hasta ahora, puede afirmarse que existen actos de omisión por desconocimiento o por voluntariedad de no integrar al currículum o los curricula, cierto tipo de contenidos. Existen temas de los que no se habla en la escuela, existen contenidos de los que no se puede hablar. Y existen agentes y niveles de competencia que los excluyen o los niegan. Por tanto, más allá de hablar de un currículum nulo por omisión o voluntariedad de negación, hablamos de la existencia de un "currículum proscrito" en el sentido del profuso destierro que el espacio ha hecho y sigue haciendo de ciertos conocimientos o de una buena parte de los mismos, arrojándolos de aquel territorio del saber donde por contrario se les debe acoger, recrear, reconstruir, revisar y producir, es decir, una prohibición de entrada del conocimiento a su propia casa, a su patria: la escuela. Siendo más mezquino el acto cuando, en contravía del sentido mismo de lo escolar, cuando por causas políticas, ideológicas, religiosas o económicas no se cuente en el currículum con determinados conocimientos o temáticas que, anuladas o negadas, terminan siendo acogidas por su sino proscrito en la doxa o "vana" opinión y el currículum basura (Martínez, 2009) de los medios de comunicación, con el consecuente infortunio de que estos últimos también son "programas, dispositivos y artefactos de producción de identidad" (p. 9) que pueden afianzar $\mathrm{y}$, en el peor de los casos, promover prácticas sociales y culturales tan complejas como la violencia directa y armada, la xenofobia o la intolerancia.

El currículum proscrito tiene eco o materialización en las distintas áreas de conocimiento, desde la enseñanza de la lengua, pasado por las matemáticas, el conocimiento del medio social, el arte y la técnica. Debiendo volver a preguntarnos tanto por el conocimiento que es seleccionado e incluido en el texto curricular, como por aquellos conocimientos que son escindidos de este, requiriéndose desarrollar en mayor medida una línea de investigación educativa que se pregunte precisamente por tales conocimientos desterrados.

\section{REFERENCIAS}

Acaso, M. (2013). Reduvolution: hacer la revolución en la educación. Madrid: Paidós. 
Ahwee, A., Chiappone, L. Cuevas, P., Galloway, F., Hart, J., Tate, B., Lones, J. Medina, A., Menendez, R., Pilonieta, P. Provenzo, E., Shook, A., Stephens, P. y Syrquin, H. (2004). The Hidden And Null Currículums: An Experiment In Collective Educational Biography. En Educational Studies. 35 (1), 25-43.

Althusser, L. (1970). Ideología y aparatos ideológicos del Estado. Medellín: Ediciones Pepe.

Apple, M. (1986). Ideología y currículo. Madrid: Akal.

Apple, M. (1997). Política educativa y programa conservador en Estados Unidos. En Revista de Educación, 313, 179-198.

Árias, D. (2010). Educación ciudadana en Colombia: políticas de la exclusión. En Nodos y nudos, 13 (29), 79-91.

Arrieta de Meza, B. y Meza, R. (2001). El currículum nulo y sus diferentes modalidades. En Revista Iberoamericana de Educación (versión digital). Recuperado de http://www.rieoei.org/deloslectores/220Meza.PDF

Assemi, A. y Sheikhzade, M. (2013). Intended, implemented and experiential null currículum. En Life Science Journal, 10(1), 82-85.

Banerjee, S. (2008). Necrocapitalism. En Organization Studies, 29, 1541-1563.

Beltrán, F. (1994). Determinaciones y el cambio en el currículum. Angulo, F. y Blanco, N. (Coord.). Teoría y desarrollo del currículum. pp. 369-384. Málaga: Aljibe.

Beltrán, F. (2010). El currículum formal: legitimidad, decisiones y descentralización. En J. Gimeno. (ed.). Saberes e incertidumbres sobre el currículum. Madrid: Morata. Bolívar, A. (2008). Didáctica y currículum: de la modernidad a la postmodernidad. Málaga: Ediciones Aljibe.

Bolívar, A., Mata, F. y Rodríguez, J. (Directores). (2006). Diccionario Enciclopédico de Didáctica. Málaga: Aljibe.

Carrión, F. (2009). El sicariato: una realidad ausente. En Revista Latinoamericana de Seguridad Ciudadana, 8, 29-40.

Da Silva, T. T. (2001). Espacios de Identidad. Barcelona: Octaedro.

De Haan, L. y Nijland, S. (2005). Rey y rey. Barcelona: Serres.

Dubet, F. (2003). Mutaciones cruzadas: la ciudadanía y la escuela. En J. Benedicto y M. L. Morán (coord.), Aprendiendo a ser ciudadanos. Experiencias sociales y construcción de la ciudadanía entre los jóvenes, pp. 219-234. Madrid: Instituto de la Juventud. 
Eisner, E. (1979). The educational imagination: on the design and evaluation of school programs. (Second edition, 1994). New Jersey: MacMillan.

Fernández, M. (1999). La escuela a examen. Un análisis sociológico para educadores y otras personas interesadas. (5ta Edición). Madrid: Pirámide.

Flinders, D. J., Noddings, N. y Thornton, S. J. (1986). The Null Curriculum: Its Theoretical Basis and Practical Implications. En Curriculum Inquiry, 16, (1) 33-42.

Franklin, B. y Johnson, C. (2006). Lo que enseñan las escuelas: una historia social del currículum en los Estados Unidos desde 1950. En Profesorado: Revista de currículum y formación del profesorado, 10 (2), 1-29.

Geertz, C. (1957). Ritual and Social Change: A Javanese Example. En American Anthropologist, 59: 32-54.

Gimeno, J. (1988). El currículum: una reflexión sobre la práctica. Madrid: Morata.

Gimeno, J. (2010). Saberes e incertidumbres sobre el currículum. Madrid: Morata.

Gimeno, J. (2013). En busca del sentido de la educación. Madrid: Morata.

Giroux, H. (2001). Cultura, política y práctica educativa. Barcelona: Graó.

Giroux, H. (2003). La inocencia robada: juventud, multinacionales y política cultural. Madrid: Morata.

Guevara, R. (2000). Currículum Nulo: ¿Cómo dijo? En Contexto Educativo - Revista digital de Educación y Nuevas Tecnologías, 8. 1-5.

Martínez, J. (2010). La ciudad en el currículum y el currículum en la ciudad. En J. Gimeno (Comp.). Saberes e incertidumbres sobre el currículum. Madrid: Morata.

McLaren, P. (1994). La vida en las escuelas: una introducción a la pedagogía crítica en los fundamentos de la educación (4 ${ }^{\mathrm{a}} \mathrm{Ed}$. 2005). México: Siglo XXI.

McLaren, P. (1997). Pedagogía crítica y cultura depredadora. Políticas de oposición en la era posmoderna. Barcelona. Paidós.

Melich, J. C. (2003). La sabiduría de lo incierto. Sobre ética y educación desde un punto de vista literario. En Educar 31, 33-45.

Nahoum, V. (2002). Cultura de la guerra y contemporaneidad: ¿la "purificación étnica" es una práctica "de otros tiempos"? En Revista Nómadas, 16, 64-74.

Pérez Gómez, A. (2004). La cultura escolar en la sociedad neoliberal. Madrid: Morata.

Popkewitz, T. (2010). Estudios curriculares y la historia del presente. En Profesorado: Revista de currículum y formación del profesorado, 14 (1), 355-370.

Posner, G. (1998). Análisis de currículo. Bogotá: McGraw-Hill. 
Scarlett, M. (2009). Imagining a world beyond genocide: teaching about transitional justice. Social Studies, 100 (4), 169-176.

Stenhouse, L. (1991). Investigación y desarrollo del curriculum. Madrid: Morata.

Torok, R. (2007). The Re-historicisation and Increased Contextualisation of Curriculum and Its Associated Pedagogies. International Journal of Pedagogies and Learning, 3(1), 67-81.

Totten, S. (2001). Addressing the "null currículum": teaching about genocides other than the holocaust. En Social Education. 65 (4), 309-314.

Torres, J. (1993). Las culturas negadas y silenciadas en el currículum. En Cuadernos de pedagogía. 217, 60-67.

Torres, J. (2007). Educación en tiempos de neoliberalismo. Madrid: Morata.

Torres, J. (2010). La justicia curricular. El caballo de Troya de la cultura escolar. Madrid. Morata.

Urteaga, E. (2009). Orígenes e inicios de los estudios culturales. En Gazeta de antropología, 25 (1), 1-17. Recuperado el 15 de septiembre de 2013, de http://hdl.handle.net/10481/6872.

Whitty, G. y Power, S. (2008). ¿Más allá del estado y el Mercado? La evolución de los modos de gobierno. En M. Casassus, M. F. Enguita y E. Terrén (Coords.). Repensando la organización escolar y nuevos desarrollos. Madrid: Akal.

Recebido para publicação em 16-09-16; aceito em 08-10-16 